\title{
Comparison of the Effect of Two Hemoplasma Species on Hematological Parameters in Cattle
}

\author{
Michihito TAGAWA ${ }^{1)}$, Kotaro MATSUMOTO ${ }^{1)}$, Naoaki YOKOYAMA ${ }^{2)}$ and Hisashi INOKUMA ${ }^{1) *}$ \\ ${ }^{1)}$ Department of Clinical Veterinary Science and ${ }^{2)}$ National Research Center for Protozoan Diseases, Obihiro University of Agriculture \\ and Veterinary Medicine, Obihiro 080-8555, Japan
}

(Received 11 July 2009/Accepted 9 September 2009/Published online in J-STAGE 13 November 2009)

ABSTRACT. Mycoplasma wenyonii and 'Candidatus Mycoplasma haemobos' are pathogens associated with bovine hemoplasmosis. Hematological parameters of these two hemoplasma species were compared in a cattle herd that was known to be infected with these 2 pathogens. ' $C$. M. haemobos'-infected cattle exhibited lower red blood cell levels, hemoglobin concentrations and packed cell volumes than $M$. wenyonii-infected cattle and hemoplasma-negative controls. On the other hand, cattle infected with $M$. wenyonii did not show any significant differences in hematological parameters compared with the hemoplasma-negative cattle.

KEY WORDS: anemia, 'Candidatus Mycoplasma haemobos', cattle, Mycoplasma wenyonii.

J. Vet. Med. Sci. 72(1): 113-115, 2010

Hemoplasmas include a number of hemotropic mycoplasmas found in the peripheral blood of animals. Mycoplasma wenyonii, which causes bovine hemoplasmosis, is a wall-less hemotrophic prokaryote previously classified as Eperythrozoon wenyonii in the order Rickettsiales, but recently assigned to the Mycoplasma genus on the basis of 16S rRNA analysis [10-12]. This species has a wide geographic distribution [13] and has also been found in Japan [6]. The clinical signs of hemoplasma infection in cattle include anemia, transient fever, lymphadenopathy, anorexia, weight loss and decreased milk production; however, in most animals, the infection remains subclinical $[9,14]$. Another species of hemoplasma in cattle, identified as ' $\mathrm{Can}$ didatus Mycoplasma haemobos', has recently been discovered in Japan using molecular methods such as polymerase chain reaction (PCR) and sequencing techniques [16]. Hemoplasma species other than $M$. wenyonii has also been found in cattle in Switzerland [4].

In small animals, multiple hemoplasma species have been characterized, including feline hemoplasmas such as Mycoplasma haemofelis, 'Candidatus Mycoplasma haemominutum' and 'Candidatus Mycoplasma turicensis' [5, 17, 18], and canine hemoplasmas such as Mycoplasma haemocanis and 'Candidatus Mycoplasma haematoparvum' [8, 15]. $M$. haemofelis induces more severe clinical symptoms in the feline host than 'Candidatus M. haemominutum' [2, 7], and 'Candidatus M. turicensis' has been reported to be a similarly weak pathogen [3]. However, little information is available on the pathogenicity of hemoplasmas in cattle. Thus, the aim of this study was to compare the hematological parameters of two different species of hemoplasma found in Japan.

EDTA-anticoagulated blood samples were collected from 103 cattle (Holstein Friesian) kept in a farm in Tokachi Dis-

\footnotetext{
* Correspondence to: InoKuma, H., Obihiro University of Agriculture and Veterinary Medicine, Inada, Obihiro, 080-8555, Japan. e-mail: inokuma@obihiro.ac.jp
}

trict, Hokkaido, Japan, on June 25th, 2007. The cattle were treated with acaricide monthly to prevent infection with Theileria orientalis and exhibited no apparent clinical signs at the time of blood collection. Hematological parameters, including white blood cell count (WBC), red blood cell count (RBC), hemoglobin concentration $(\mathrm{Hb})$, mean corpuscular volume (MCV), mean cell hemoglobin $(\mathrm{MCH})$, mean cell hemoglobin concentration (MCHC) and platelet (PLT) count were measured using an automated cell counter (Celltac $\alpha$; Nihon Koden).

DNA was extracted using a QIAamp DNA Blood Mini Kit (QIAGEN, Hilden, Germany) according to the manufacturer's instructions. DNA samples were stored at $-30^{\circ} \mathrm{C}$ until use. To detect hemoplasma infection, PCR amplification was performed in a $25 \mu \mathrm{l}$ reaction mixture containing 5 $\mu l$ of each DNA template and an F2/R2 primer set [7]. These primers amplify the $16 \mathrm{~S}$ rRNA genes of most hemoplasma, including M. haemofelis, M. haemocanis, 'Candidatus M. haemominutum', 'Camdidatus M. haemopurvum', M. wenyonii and 'Candidatus M. haemobos' [7, 16]. PCR products were electrophoresed on a $1.5 \%$ agarose gel in Tris-borate-EDTA (TBE) buffer, stained with ethidium bromide, and visualized under a UV transilluminator. The longer fragment (193 bp) was identified as $M$. wenyonii DNA, and the shorter fragment (170 bp) was identified as 'Candidatus M. haemobos' DNA [16].

The presence of hemoplasma was detected in 23 of the 103 (22.3\%) bovine blood samples from the individual cattle by PCR. Among the 23 positive samples, 14 were found to be positive for only $M$. wenyonii, seven were positive for only 'Candidatus M. haemobos' and two showed dual infection. The remaining 80 cattle were hemoplasma-negative.

The Mann-Whitney test was performed to compare the hematological parameters of the $M$. wenyonii-infected $(\mathrm{n}=14)$, 'Candidatus M. haemobos'-infected $(\mathrm{n}=7)$ and hemoplasma-negative cattle $(\mathrm{n}=80) . P$-values of 0.05 were 
Table 1. Hematologic examination of hemoplasma-infected and hemoplasma-negative cattle

\begin{tabular}{|c|c|c|c|c|}
\hline Parameters & $\begin{array}{l}\text { M. wenyonii } \\
\text { infection } \\
(\mathrm{n}=14)\end{array}$ & $\begin{array}{c}\text { C. M. haemobos } \\
\text { infection } \\
(\mathrm{n}=7)\end{array}$ & $\begin{array}{l}\text { Hemoplasma } \\
\text {-negative } \\
(\mathrm{n}=80)\end{array}$ & $\begin{array}{l}\text { Dual infection } \\
\qquad(\mathrm{n}=2)\end{array}$ \\
\hline \multicolumn{5}{|c|}{$\mathrm{WBC}\left(\times 10^{2} / \mu l\right)$} \\
\hline Mean & $136.4 *$ & 110.0 & 108.5 & 107.5 \\
\hline$\pm \mathrm{SD}$ & 47.6 & 26.4 & 27.3 & - \\
\hline \multicolumn{5}{|c|}{$\mathrm{RBC}\left(\times 10^{4} / \mu l\right)$} \\
\hline Mean & 776.9 & $678.9 *$ & 816.5 & 659.5 \\
\hline$\pm \mathrm{SD}$ & 78.4 & 86.3 & 168.4 & - \\
\hline \multicolumn{5}{|l|}{$\mathrm{Hb}(\mathrm{g} / \mathrm{d} l)$} \\
\hline Mean & 11.1 & $9.7 *$ & 11.1 & 9.8 \\
\hline$\pm \mathrm{SD}$ & 1.4 & 0.7 & 1.3 & - \\
\hline \multicolumn{5}{|l|}{ PCV $(\%)$} \\
\hline Mean & 33.7 & $31.3^{*}$ & 33.3 & 32.2 \\
\hline$\pm \mathrm{SD}$ & 2.6 & 1.8 & 3.0 & - \\
\hline \multicolumn{5}{|l|}{$\operatorname{MCV}(\mathrm{fl})$} \\
\hline Mean & 43.8 & $46.7 *$ & 40.9 & 48.9 \\
\hline$\pm \mathrm{SD}$ & 4.9 & 6.2 & 6.1 & - \\
\hline \multicolumn{5}{|l|}{$\mathrm{MCH}(\mathrm{pg})$} \\
\hline Mean & 14.4 & 13.0 & 14.7 & 14.9 \\
\hline$\pm \mathrm{SD}$ & 1.7 & 5.1 & 11.4 & - \\
\hline \multicolumn{5}{|l|}{$\operatorname{MCHC}(\mathrm{g} / \mathrm{d} l)$} \\
\hline Mean & 33.0 & 31.1 & 33.7 & 30.5 \\
\hline$\pm \mathrm{SD}$ & 2.4 & 2.1 & 5.3 & - \\
\hline \multicolumn{5}{|c|}{ PLT $\left(\times 10^{4} / \mu l\right)$} \\
\hline Mean & 41.3 & 49.8 & 50.7 & 40.4 \\
\hline$\pm \mathrm{SD}$ & 28.3 & 28.1 & 30.8 & - \\
\hline
\end{tabular}

* $P<0.05, \mathrm{SD}=$ standard deviation.

considered statistically significant for all tests in this study. The 2 samples that tested dual positive for $M$. wenyonii and 'Candidatus M. haemobos' were excluded from the statistical analysis.

The results are summarized in Table 1 . The mean $\mathrm{RBC}$, $\mathrm{Hb}$, and packed cell volume (PCV) levels of the 'Candidatus $\mathrm{M}$. haemobos'-infected cattle were all significantly lower than those of the $M$. wenyonii-infected and hemoplasma-negative cattle, but no significant differences were found in the mean RBC, Hb, and PCV levels between the $M$. wenyonii-infected and hemoplasma-negative cattle. The mean MCV of the 'Candidatus M. haemobos'-infected cattle was significantly higher than that of the $M$. wenyoniiinfected and hemoplasma-negative cattle. No significant differences were found in MCH, MCHC and PLT levels among the three groups.

Hemoplasmas attach to the surface of the host animal erythrocytes and induce changes in the erythrocyte membrane. Hemolytic anemia is caused by the production of secondary anti-erythrocyte autoantibodies [1]. Thus, we suspected that the anemia indicators (RBC, Hb, and PCV) of cattle infected with hemoplasma would decrease and that $\mathrm{MCV}$ would increase. In the present study, lower $\mathrm{RBC}, \mathrm{Hb}$ and PCV levels and higher MCV levels were found in the 'Candidatus M. haemobos'-infected cattle than in the $M$. wenyonii-infected and hemoplasma-negative cattle. Our results suggested that the effect of 'Candidatus M. haemobos' infection on the hematological parameters might be more stronger than that of $M$. wenyonii infection and that some level of hemolytic anemia may have been present in the 'Candidatus M. haemobos'-infected cattle.

In our previous report, phylogenetic analysis based on the $16 \mathrm{~S}$ rRNA gene revealed that 'Candidatus M. haemobos' is closely related to feline $M$. haemofelis [16], which induces more severe clinical symptoms in cats than 'Candidatus $\mathrm{M}$. haemominutum' $[2,7]$. Dual infection with both $M$. haemofelis and 'Candidatus M. haemominutum' reportedly induces more severe anemia in feline hemoplasmosis [18]. In the present study, the $\mathrm{RBC}, \mathrm{Hb}$ and $\mathrm{PCV}$ levels of the dual infected cattle were lower than the levels of the ' $\mathrm{Candi}$ datus M. haemobos'-infected cattle; however, statistical analysis was not possible due to the small number of samples.

The WBC levels of the $M$. wenyonii-infected cattle were significantly higher than those of the 'Candidatus Mycoplasma haemobos'-infected and hemoplasma-negative cattle $(P<0.01)$; however, the reasons for these results are unclear.

This is the first study to compare the effect of 2 different species of bovine hemoplasmas, $M$. wenyonii and 'Candidatus M. haemobos', on hematological parameters in infected cattle. Although no apparent clinical signs were observed in the cattle in the present study, hemoplasma infection affected hematological parameters of the cattle. Because we studied a relatively small number of cattle in this study, further investigation is required to confirm our findings that 
'Candidatus M. haemobos' is more pathogenic than $M$. wenyonii.

ACKNOWLEDGMENT. This work was supported in part by a Grant-in-Aid for Scientific Research from the Japan Society for the Promotion of Science (Nos. 18380185 and 21380192).

\section{REFERENCES}

1. Breitschwerdt, E. B. 2000. The rickettsioses. pp. 400-408. In: Textbook of Veterinary Internal Medicine. 5th ed. (Ettinger, S. J. and Feldman, E. C. eds.), W. B. Saunders, Philadelphia.

2. Foley, J. E., Harrus, S., Poland, A., Chomel, B. and Pedersen, N. C. 1998. Molecular, clinical, and pathologic comparison of two distinct strains of Haemobartonella felis in domestic cats. Am. J. Vet. Res. 59: 1581-1588.

3. Fujiwara, M., Watanabe, M., Yamada, T. and Harasawa, R. 2007. Occurrence of 'Candidatus Mycoplasma turicensis'Infection in domestic cats in Japan. J. Vet. Med. Sci. 69: 1061-1063.

4. Hoffmann-Lehmann, R., Meli, M.L., Dreher, U. M., Gonczi, E., Deplazes, P., Braun, U., Engels, M., Schupbach, J., Thoma, R., Griot, C., Stark, K.D.C., Willi, B., Schmidt, J., Kocan, K.M. and Lutz, H. 2004. Concurrent infection with vectorborne pathogens associated with fatal hemolytic amemia in a cattle herd in Switzerland. J. Clin. Microbiol. 42: 3775-3780.

5. Inokuma, H., Taroura, S., Okuda, M., Hisasue, M., Itamoto, K., Une, S., Nakaichi, M. and Taura, Y. 2004. Molecular survey of Mycoplasma haemofelis and 'Candidatus Mycoplasma haemominutum' infection in cats in Yamaguchi and surrounding areas. J. Vet. Med. Sci. 66: 1071-1020.

6. Ishihara, T. 1962. Eperythrozoonosis in cattle in Japan. Natl. Inst. Anim. Health Q. 2: 21-30.

7. Jensen, W. A., Lappin, M. R., Kamkar, S. and Reagen, W. J. 2001. Use of a polymerase chain reaction assay to detect and differentiate two strains of Haemobartonella felis in naturally infected cats. Am. J. Vet. Res. 62: 604-608.

8. Kenny, M. J., Shaw, S. E., Beugnet, F. and Tasker, S. 2004. Demonstration of two distinct hemotropic mycoplasmas in French dogs. J. Clin. Microbiol. 42: 5397-5399.

9. Montes, A. J., Wolfe, D. F., Welles, E. G., Tyler, J. W. and
Tepe, E. 1994. Infertility associated with Eperythrozoon wenyonii infection in a bull. J. Am. Vet. Med. Assoc. 204: 261263.

10. Neimark, H. and Kocan, K. M. 1997. The cell wall-less rickettsia Eperythrozoon wenyonii is a Mycoplasma. FEMS Microbiol. Lett. 156: 287-291.

11. Neimark, H., Johansson, K. E., Rikihisa, Y. and Tully, J. G. 2001. Proposal to transfer some members of the genera Haemobartonella and Eperythrozoon to the genus Mycoplasma with descriptions of 'Candidatus Mycoplasma haemofelis' 'Candidatus Mycoplasma haemomuris' 'Candidatus Mycoplasma haemosuis' and 'Candidatus Mycoplasma wenyonii'. Int. J. Syst. Evol. Microbiol. 50: 891-899.

12. Neimark, H., Johansson, K. E., Rikihisa, Y. and Tully, J. G. 2002. Revision of haemotrophic Mycoplasma species names. Int. J. Syst. Evol. Microbiol. 52: 683.

13. Scott, G. R. and Woldehiwet, Z. 1993. Eperythrozoonosis. pp. 111-129. In: Rickettsial and Chlamydial Diseases of Domestic Animals (Woldehiwet, Z. and Ristic, M. eds.), Pergamon Press, Oxford.

14. Smith, J. A., Thrall, M. A., Smith, J. L., Salman, M. D., Ching, S. V. and Collons, J. K. 1990. Eperythrozoon wenyonii infection in dairy cattle. J. Am. Vet. Med. Assoc. 196: 1244-1250.

15. Sykes, J. E., Ball, L. M., Bailiff, N. L. and Fry, M. M. 2005. 'Candidatus Mycoplasma haematoparvum', a novel small haemotropic mycoplasma from a dog. Int. J. Syst. Evol. Microbiol. 55: $27-30$.

16. Tagawa, M., Matsumoto, K. and Inokuma, H. 2008. Molecular detection of Mycoplasma wenyonii and 'Candidatus Mycoplasma haemobos' in cattle in Hokkaido, Japan. Vet. Microbiol. 132: 177-180.

17. Willi, B., Boretti, F. S., Cattori, V., Tasker, S., Meli, M. L., Reusch, C., Lutz, H. and Hofmann-Lehmann, R. 2005. Identification, molecular characterization, and experimental transmission of a new hemoplasma isolate from a cat with hemolytic anemia in Switzerland. J. Clin. Microbiol. 43: 2581-2585.

18. Willi, B., Tasker, S., Boretti, F. S., Doherr, M. G., Cattori, V., Meli, M. L., Lobetti, R. G., Malik, R., Reusch, C. E., Lutz, H. and Hofmann-Lehmann, R. 2006. Phylogenic analysis of ' Candidatus Mycoplasma turicensis' isolates from pet cats in the United Kingdom, Australia, and South Africa, with analysis of risk factors for infection. J. Clin. Microbiol. 44: 4430-4435. 